\title{
Obstructive Sleep Apnoea: A Risk Factor for Hypertension
}

\author{
Ozaifa Kareem', Masood Tanvir'2, Amreen Naqash', and G. N. Bader ${ }^{1 *}$ \\ 'Department of Pharmaceutical Sciences, University of Kashmir, Hazratbal Srinagar, Kashmir, India \\ ${ }^{2}$ Department of General Medicine, Government Medical College Srinagar, India
}

Article Info

\section{Article Notes}

Received: March 23, 2018

Accepted: April 27, 2018

\section{*Correspondence:}

Dr. Ghulam N. Bader, Department of Pharmaceutical Sciences, University of Kashmir, Hazratbal Srinagar, Kashmir-190006, India;

E-mail: gnbader@kashmiruniversity.ac.in;

(c) 2018 Bader GN. This article is distributed under the terms of the Creative Commons Attribution 4.0 International License.

\section{Key words:}

Obstructive Sleep Apnoea

Hypertension

Apnoea

Sympathetic activation

\section{ABSTRACT}

Obstructive Sleep Apnoea (OSA) is the most prevalent condition among sleep disordered breathing that leads to increased risk of cardiovascular (CV) and cerebrovascular morbidity and mortality. The most common comorbidity associated with OSA is systemic hypertension (HTN). Various epidemiological studies suggest a link between OSA and hypertension that involves complex interactions between various pathophysiological mechanisms and metabolic risk factors. OSA causes changes in normal physiological functions during nocturnal apneic episodes which in-turn lead to daytime hypertension. The widely accepted mechanisms by which the OSA contributes to the development of hypertension include sympathetic activation, inflammation, oxidative stress, and endothelial dysfunction. OSA and hypertension coexist in millions of people and both have been associated with heart disease, stroke, and premature death. Worldwide the prevalence of hypertension in OSA is estimated between 30 and $70 \%$, thus setting it off as a major public health problem. Furthermore, not only has OSA been implicated in causing new hypertension but also it is said to promote resistant hypertension in already existent hypertensive patients, which may further grim the clinical and therapeutic outcomes. It is necessary to recognize the underlying OSA in-order to decrease the overall healthcare burden in terms of rigorous antihypertensive therapy instituted to OSA subjects. The review summarizes an up-to-date scenario of obstructive sleep apnoea as a cause of systemic hypertension and the overall cardiovascular risks.

\section{Introduction}

In 2010, the global age-standardized prevalence of hypertension in adults aged $\geq 20$ years was reported $31.1 \%{ }^{1}$. It is the major cause of cardiovascular mortality and morbidity among adults. The World Health Organization (WHO) has identified hypertension as one of the most important preventable causes of premature morbidity and mortality ${ }^{2}$. In 2014, the overall prevalence of hypertension in India was reported to be $29.8 \%$ of which $33 \%$ and $25 \%$ were urban and rural population respectively ${ }^{3}$. It is labeled as the third most common risk factor for the burden of diseases in South Asia ${ }^{4}$. From 2011-2014, nearly $30.4 \%$ of adults aged $\geq 20$ years were reported to be hypertensive in USA alone ${ }^{5}$. According to the new guideline, published in November 2017 by The American Heart Association (AHA), hypertension is defined as a systolic blood pressure more than $130 \mathrm{~mm} \mathrm{Hg}$ and diastolic blood pressure more than $80 \mathrm{~mm}$ $\mathrm{Hg}^{6}$. As per this report, the prevalence of hypertensive individuals is extremely high and previous studies most likely underestimate the prevalence in this context. On the other hand, obstructive sleep 
apnoea (OSA), also known as obstructive sleep apnoeahypopnea, is a disorder that involves repetitive episodes of complete or partial cessation of airflow (breathing) during sleep, due to collapse of the upper airway (Oropharyngeal tract) with a consequent decrease in oxygen saturation ${ }^{7}$. The airway collapse during sleep leads to fragmented sleep pattern. During the brief period of breathing obstruction, in severe OSA, intermittent hypoxia with bursts in sympathetic nerve activity occur. This sympathetic over activity results in increased heart rate and blood pressure (BP). The severity of OSA is determined by Apnoea-Hypopnoea-Index (AHI), which is defined as the total number of periods of breathing pauses per hour of sleep ${ }^{8}$. Different populations and age groups present a varying set of prevalence of OSA $^{9}$. It is an emerging health problem, particularly in high income countries ${ }^{10}$. Its high disease burden is related to both the health care costs attributable to OSA alone and as an independent risk factor for cardiovascular, metabolic, and psychiatric disorders such as hypertension, stroke, diabetes, and depression which are global health priorities $^{11,12}$. According to American Sleep Association,25 million adults in United States have OSA with nearly 9-21\% of women and $24-31 \%$ of men $^{13}$. Generally, $34 \%$ of men and $17.4 \%$ of women between the $30-70$ years of age are expected to have an $\mathrm{AHI} \geq 5^{14}$. Various cross-sectional and longitudinal studies suggest an association between OSA and hypertension ${ }^{15,16,17}$. Also, resistant, chronic and longstanding hypertension is purportedly caused by untreated or underdiagnosed $\mathrm{OSA}^{18,19}$.

A study by Grote and colleagues reported that the prevalence of hypertension was higher in patients with OSA and vice-versa ${ }^{20}$. Additionally, a study conducted in 709 subjects conferred a three-fold risk of being diagnosed with hypertension over a follow-up period of four-year in association with the presence of severe OSA at the enrollment of study ${ }^{17}$. Population-based cohorts find an increased prevalence and incidence of hypertension in adults with OSA, which remains significant after controlling important confounding factors such as obesity ${ }^{21}$.

\section{Normal Sleep Pattern And Blood Pressure}

Sleep is a state of unconsciousness in which the brain is relatively more responsive to internal than external stimuli $^{22}$. In healthy individuals, $10-15 \%$ reduction in systolic and diastolic blood pressure occurs during sleep compared to wakefulness ${ }^{23}$. This decrease in BP during sleep in normal individuals is referred to as "BP dipping" or "dipping pattern". The dipping pattern is a physiological reaction in response to the sympathetic withdrawal and parasympathetic dominance occurring during transition from wakefulness to non-rapid eye movement (NREM) sleep $^{24}$. The interaction between circadian rhythm and sleep-wake cycle causes diurnal variations in cardiovascular activity which is high during day and gradually decreases during night-time, as sleep sets in. During NREM sleep BP, heart rate, cardiac output, and systemic vascular resistance are lowered while during rapid eye movement (REM) sleep brief surges in sympathetic nerve (SN) activity, heart rate and BP occur ${ }^{25}$. Since REM sleep constitutes only $20 \%$ of total sleep cycle, an overall reduction in cardiovascular functions occur $^{25,26}$. A less than $10 \%$ decrease in nocturnal dipping is referred to as non-dipping which is attributed to be the strong, independent predictor of cardiovascular risk ${ }^{26}$.

\section{Nocturnal BP Pattern In Patients With OSA}

The alteration in the physiological nocturnal BP decrease (dipping pattern) occurs in patients with OSA, predisposing them to cardiovascular risks ${ }^{27}$. The nighttime BP is an important indicator of overall cardiovascular risk as well as daytime $\mathrm{BP}^{28}$. The diminished/absence of nocturnal dipping makes the patients more liable of developing diseases like chronic kidney disease, hypertension, diabetes, resistant hypertension beside others. The subjects with OSA as compared to the normal subjects exhibit a high prevalence of unfavorable circadian pattern using 24 hour-Ambulatory blood pressure measurement (ABPM) ${ }^{29}$. A cross-sectional study, including 84 patients, concluded that fragmented sleep pattern (seen in OSA) is associated with the non-dipping pattern i.e. less BP decrease during sleep ${ }^{30}$. A similar prospective study conducted in 140 patients with hypertension found a higher dipping ratio (ratio between the mean nighttime BP and the mean daytime BP) in patients with OSA compared to individuals without $\mathrm{OSA}^{31}$. Another prospective cohort Ohasama study, including 1464 patients, reported that daytime BP measured by 24-hr ABPM was linearly related to stroke risk and $20 \%$ greater cardiovascular mortality is associated with every $5 \%$ deficiency in the normal decline in nocturnal $\mathrm{BP}^{32}$. A high nocturnal BP (SBP $\geq 120 \mathrm{~mm} \mathrm{Hg}$ and/or DBP $\geq 70 \mathrm{~mm} \mathrm{Hg}$ ) is the most important predictor of cardiovascular ${ }^{33}$ and cerebrovascular outcomes ${ }^{34}$. Thus, ABPM is a superior clinical measure for the determination of nighttime BP which is particularly important in patients taking anti-hypertensive medications because such subjects present normal daytime BP (masking the need for cardiovascular risk evaluation). The patients with OSA have a markedly raised nighttime BP making ABPM a strong prognostic test.

\section{Pathophysiological Mechanisms Promoting Hypertension In OSA}

There is an interplay of mechanisms that play a role in the development of hypertension in patients with OSA. The most agreed upon and acceptable mechanisms are:

\section{Sympathetic activation}

The most plausible mechanism by which OSA contributes to the elevation in BP is through acute (chronic in case of 
long standing OSA) surges in SN activity. The outcome of these surges in SN activity manifest throughout the day as sustained effect in comparison to control subjects ${ }^{35}$. The repetitive episodes of hypoxemia and hypercapnia caused by reduced ventilation during airway obstruction elicit reflex changes in sympathetic and parasympathetic activity $^{36}$. The derangements in chemo-reflex activity due to intermittent hypoxia along with elevated levels of catecholamine during daytime have been attributed to cause hypertension ${ }^{37}$. The micro arousals from sleep due to breathing cessation induce negative intrathoracic pressure and reduce the pulmonary stretch receptor activation ${ }^{38}$. These changes activate sympathetic response, causing rise in $\mathrm{BP}^{39}$. Both animal and human studies have exhibited the role of hypoxia on BP levels. In a canine model, four dogs were subjected to OSA induction and subsequently checked for daytime and nighttime BP during and after 1-3 months. The study concluded that OSA resulted increase in nighttime $\mathrm{BP}$ (mean $\pm \mathrm{SEM}$ of $13 \pm 2.0 \mathrm{~mm} \mathrm{Hg}$ ) and eventually increased the daytime BP $(15.7 \pm 4.3 \mathrm{~mm} \mathrm{Hg})^{40}$. A human study comprising 12 healthy subjects has shown that the consistent 2-week intermittent hypoxia increases systolic BP by $8 \mathrm{~mm} \mathrm{Hg}$ and diastolic BP by $5 \mathrm{~mm} \mathrm{Hg}^{41}$.

\section{Inflammation}

An inflammatory reaction occurs in response to repeated hypoxemic episodes during sleep in OSA. The oxygen desaturation followed by rapid re-saturation (characterized as intermittent hypoxia), sets off a cascade of responses in the body. The most noteworthy inflammatory biomarkers include interleukin-1 (IL-1), interleukin-8 (IL-8), high sensitivity C-reactive protein (hs-CRP), tumor necrosis factor- $\alpha$ (TNF- $\alpha$ ), soluble intercellular adhesion molecules (sICAM), interleukin-6 (IL-6) and RANTES (Regulated on Activation, Normal $\mathrm{T}$ cells expressed and Secreted ${ }^{42}$. Some of these biomarkers (especially CRP) are thought to be responsible for increased atherosclerotic risk, endothelial dysfunction and elevated $\mathrm{BP}^{43}$. The TNF- $\alpha$ levels in OSA show an independent association with oxygen desaturation index, thus supporting the role of intermittent hypoxia as a trigger to inflammatory response ${ }^{44}$. A recent study conducted in 80 patients with OSA and 40 controls concluded that the former group had elevated levels of hs-CRP, TNF- $\alpha$ and IL- 6 and increased thickness of carotid-intima, promoting atherosclerotic lesions. A new biomarker, known as Pentraxin-3 was also shown to be increased in patients with OSA $^{45}$. The other novel biomarkers discovered, having a role in developing hypertension in OSA include Nesfatin-1, Fibrinogen, and YKL-40 (also referred to as human cartilage glycoprotein) ${ }^{42}$. A study successfully demonstrated the protective effects of atorvastatin against deleterious effects of inflammation on cardiovascular consequences induced by chronic intermittent hypoxia using murine model ${ }^{46}$.

\section{Activation of the renin-angiotensin-aldosterone system}

Renin-angiotensin-aldosterone system (RAAS) has a well-established role to play in the development of hypertension. Firstly, Angiotensin is converted to Angiotensin I by renin which is further converted to Angiotensin II by angiotensin-converting-enzyme (ACE) ${ }^{47}$. An increase in BP is noted when Angiotensin II binds to its receptor 'Angiotensin II receptor type I' (AT1). Since Angiotensin II is a potent vasoconstrictor, it causes aldosterone secretion which results in fluid retention and hence BP elevation. In proximal tubules of kidney, the levels of renin and aldosterone have a direct elevating effect on BP, on the other hand, inhibition of ACE, Angiotensin II or AT1 lowers $\mathrm{BP}^{48}$. A study conducted in 325 newly hypertensive patients, found a high prevalence of primary aldosteronism and a positive correlation between severity of OSA and plasma renin activity in patients with $\mathrm{OSA}^{49}$. Another randomized controlled trial demonstrated that by blocking the Angiotensin II receptors the increase of BP from intermittent hypoxia can be prevented ${ }^{50}$. Yet another recent study suggests that OSA is associated with RAAS activation and OSA subjects have higher levels of Angiotensin II and aldosterone compared to control ${ }^{51}$.

\section{Oxidative stress}

Oxidative stress is defined as an imbalance between anti-oxidant and pro-oxidant systems, resulting in excessive production of reactive oxygen species (ROS). Intermittent, hypoxia is the prime event that triggers oxidative changes. It is considered analogous to ischemia/reperfusion (I/R) because hypoxemia causes quick changes in the oxygenation of blood which serves as a nidus for the injury due to ROS production ${ }^{52}$. The blockade of NO synthase and subsequent reduced bioavailability of NO causes vasoconstriction which acts as an initiator of promoter of cardiovascular diseases in OSA. Oxidative stress results in enhanced release of superoxide by leucocytes, reduced bioavailability of nitric-oxide (NO), and reduced antioxidant capacity ${ }^{53}$. The other biomarkers that promote cardiovascular risks (particularly hypertension) include ROS production in peripheral neutrophils (provoked by intermittent hypoxia), ${ }^{54} 8$-isoprostane levels in blood ${ }^{55}$ and 8-isoprostane in exhaled breath condensate ${ }^{56}$.

\section{Endothelial dysfunction}

Endothelial dysfunction, resulting from intermittent hypoxia, is an early precursor to the development of atherosclerosis and hypertension preceding cardiovascular disease in $\mathrm{OSA}^{57}$. A normal vascular structure and function is maintained by endothelium through the release of mediators like NO, Angiotensin II and endothelin-1 (ET-1). Endothelial dysfunction occurs when the vasoconstrictor 
mediators (Ang-II, ET-1) overpower vasodilator mediators (NO) causing arterial wall damage ${ }^{58}$. Hypoxia/reoxygenation associated with transient cessation of airflow in OSA affects NO production and promotes oxidative stress. This in-turn decreases the transcription and activation of endothelial nitric oxide synthase (eNOS) by suppressing its phosphorylation ${ }^{59}$. Among ROS, superoxide rapidly scavenges NO generating peroxynitrile (a toxic metabolite that nitrosylates tyrosine residues, forming nitrotyrosine $e^{60}$ ) in the microvascular walls of OSA subjects ${ }^{61}$. As endothelial oxidative stress increases and fewer cofactors are available for NO synthesis, eNOS preferentially promotes superoxide production that hastens NO degradation and reduces its availability causing a vicious cycle $^{59}$. A study concluded that the patients with OSA and hypertension had prominent impairment of endothelialdependent vasodilator capacity ${ }^{62}$. Thus, endothelial dysfunction and inhibition of NO production in OSA is implicated in the OSA-related hypertension ${ }^{63}$.

\section{Epidemiological Association of OSA And Hypertension}

Population and community-based studies indicate that patients with OSA exhibit a high prevalence of hypertension and vice-versa ${ }^{64,16}$. The two conditions co-exist in millions of people with OSA serving as a risk factor for hypertension ${ }^{65}$. OSA is a highly prevalent disorder in patients with systemic hypertension. A recent cross-sectional study conducted by Muxfeldt and colleagues at Brazil University Hospital concluded that $20 \%-40 \%$ of individuals with hypertension suffered from OSA. The levels were even higher in resistant hypertensive patients with $82.2 \%$ having OSA and 55.5\% having severe/moderate $\mathrm{OSA}^{66}$. The prevalence of OSA in consonance with hypertension was nearly $64 \%{ }^{67}$. A study by Demede and co-workers reported a 2.5 -fold higher risk of OSA in patients with resistant hypertension in comparison to other hypertensive subjects ${ }^{68}$. A number of cross-sectional studies have accounted high prevalence of OSA in hypertension and vice-versa which may vary according to age ${ }^{69}, \mathrm{BMI}^{9}$, $\operatorname{sex}^{70}$ etc. According to AHA and JNC 8 guidelines OSA is one of the most common secondary cause of hypertension ${ }^{71}$. Various epidemiological studies conducted so far confirm that OSA is a common secondary cause of hypertension. Table 1 gives an overview of studies conducted till date which also confirms the bidirectional association between hypertension and OSA.

\section{Treatment Of OSA}

The goals of treatment are to resolve signs and symptoms of OSA, improve sleep quality, and normalize the AHI and oxyhemoglobin saturation levels. OSA should be approached as a chronic disease requiring longterm, multidisciplinary management. There are medical, behavioral, and surgical options for the treatment of OSA. Numerous randomized trials have found that effective treatment of OSA [i.e. continuous positive airway pressure (CPAP) or mandibular advancement devices (MAD)] reduce systemic blood pressure, regardless of whether the patients are hypertensive at baseline, and thus proving a causal relationship ${ }^{72}$.

\section{Behavioral Approaches}

Several behavioral approaches are recommended

Table 1: Population based studies on epidemiology of OSA in hypertension.

\begin{tabular}{|c|c|c|c|c|}
\hline Authors & $\begin{array}{l}\text { Number of } \\
\text { Subjects (n) }\end{array}$ & Study design & Duration & Results \\
\hline Peppard etal. $2000^{21}$ & 709 & Prospective population-based & 4 years & $\begin{array}{l}\text { Odds ratios for the presence of hypertension were } 1.42 \\
\text { with an } A H I \text { ofo.1 to } 4.9 \text { events/h at base line as com- } \\
\text { pared with none, } 2.03 \text { with an } A H I \text { of } 5.0-14.9 / \mathrm{h} \text {, and } 2.89 \\
\text { with an } A H I \geq 15.0 / h \text {. }\end{array}$ \\
\hline Lavie et al. $2000^{64}$ & 2677 & Population based cohort & 10 years & $\begin{array}{l}36.5 \% \text { with mild, } 46 \% \text { with moderate and } \\
53.6 \% \text { with severe OSA had hypertension }\end{array}$ \\
\hline Nieto et al. $2000^{16}$ & 6132 & Cross-sectional & 3 years & $\begin{array}{l}43 \% \text { with } \mathrm{AHI}<1.5 / \mathrm{h}, 53 \% \text { with } \mathrm{AHI} 1.5-4.9 / \mathrm{h}, 59 \% \text { with } \\
\text { AHI } 5-14.9 / \mathrm{h} \text { and } 67 \% \text { with } \mathrm{AHI} \geq 30 / \mathrm{h} \text { had hypertension }\end{array}$ \\
\hline Mubaril et al. $2017^{95}$ & 258 & Retrospective & 1 year & $36 \%$ had OSA with hypertension \\
\hline Wali et al. $2017^{96}$ & 346 & Cross-sectional case-control & 2 years & $\begin{array}{l}\text { 67.9\% had OSA with an apnoea-hypopnea } \\
\text { index (AHI) of } \geq 5\end{array}$ \\
\hline Arnardottir et al. $2016^{97}$ & 415 & Prospective cohort & 2 years & $\begin{array}{l}\text { OSA with } \geq 5 \text { AHI: } 43.1 \% ; \mathrm{AHI} \geq 5 \text { to }<15: 24.6 \% ; \mathrm{AHI} \geq 15 \text { to } \\
<30: 13.7 \% \text {; } \geq 30 \mathrm{AHI}: 4.8 \%\end{array}$ \\
\hline Shirani et al. $2016^{98}$ & 385 & Cross-sectional & 2 years & 74.5\% had hypertension with OSA \\
\hline Heinzer et al. $2015^{14}$ & 3042 & Population-based & 4 years & $\begin{array}{l}71.9 \% \text { had OSA with } A H I \geq 5 ; 36.1 \% \text { with } \\
A H I \geq 15 ; 14.5 \% \text { with } A H I \geq 30\end{array}$ \\
\hline Min et al. $2015^{99}$ & 475 & Retrospective & 3 years & $\begin{array}{l}\text { 75.6\% had OSA with hypertension and } \\
87.7 \% \text { had OSA with resistant hypertension }\end{array}$ \\
\hline Tkacova et al. $2014{ }^{100}$ & 11,911 & Prospective cohort & 6 years & $78 \%$ had $\mathrm{AHI} \geq 5$ events $/ \mathrm{h}$ \\
\hline Marin et al. $2012^{17}$ & 1889 & Prospective cohort & 17 years & $37.3 \%$ had incident hypertension \\
\hline Gonçalves et al. $2007^{101}$ & 133 & Case control & 2 years & $71 \%$ had OSA with resistant hypertension \\
\hline
\end{tabular}


to treat OSA which include avoidance of alcohol ${ }^{73}$ and sedatives before sleep (they aggravate apnoea), avoiding supine sleep position, ${ }^{74}$ and weight loss. Weight loss improves or eliminates apnoea in virtually all over-weight patients, as evident after surgically induced weight loss procedure $^{75}$.

\section{Mechanical Measures}

Mechanical measures include positive airway pressure with CPAP or bi-level positive airway pressure (Bi-PAP) device and oral appliance therapy. However, the firstline therapy used in most patients with obstructive sleep apnoea syndrome is nasal continuous positive airway pressure, commonly called nasal CPAP (nCPAP) ${ }^{7}$.

1. Continuous positive airway pressure: It is generally administered through nose and is considered the gold standard treatment for OSA. Invented in 1983 by Dr. Sullivan, it is now recommended as the first choice treatment for patients with moderate to severe OSA $^{76}$. The CPAP device consists of a blower unit that produces continuous positive-pressure airflow. This air flow is usually applied at the nose and is then directed through the upper airway. CPAP increases the lateral dimensions of the upper airway and thins the lateral pharyngeal walls, which are thicker in patients with OSA ${ }^{77}$. Effectively, CPAP works by pneumatically splinting the pharyngeal airway and thus substantially reducing or reversing the subjective and objective sleepiness associated with $\mathrm{OSA}^{78}$. CPAP significantly improves quality of life indices and normalizes blood pressure in hypertensive patients. Newer devices auto-titrate the lowest pressure required to keep the airway open eliminating the need for CPAP titration in the laboratory ${ }^{79}$.

2. Bi-level positive airway pressure (Bi-PAP):BiPAP ventilation provides two different levels of pressure (higher during inhalation and lower during expiration) and can potentially treat OSA at a lower mean pressure than CPAP, at the same time improving lung ventilation via a pressure support ${ }^{80}$. It provides a valid alternative in patients intolerant to CPAP and in patients with associated hypoventilation or chronic obstructive pulmonary disease (COPD) ${ }^{81}$.

3. Oral Appliances: These devices are designed to advance the mandible thereby pulling the tongue structure forward and opening the pharyngeal airway $^{82}$. The success rate of these devices is generally $40-60 \%$ with a greater percentage of patients showing improvement in respiratory disturbance index ${ }^{83}$. The most commonly used oral appliances reduce upper airway collapse by advancing the mandible and thus are known as mandible advancement devices (MAD) ${ }^{82}$.

\section{Surgical Interventions}

Surgical modes of therapy may be beneficial in selected patients but are not considered as primary therapy for OSA. This mode of treatment is most effective in patients having OSA because of a severe surgically correctable obstructing lesion in the upper airway, such as, tonsillar hypertrophy, adenoid hypertrophy, or craniofacial abnormalities ${ }^{8}$.

1. Uvulopalatopharyngoplasty (UPPP):UPPP (conventional or laser assisted) is the most common procedure performed in patients with OSA. It involves the resection of redundant soft tissue in the upper airway (uvula: part of the soft palate and tissue excess in the oropharynx) and is usually performed with simultaneous tonsillectomy ${ }^{84}$. The success rate of UPPP ranges from $30 \%$ (performed alone) to $60 \%$ (performed with tonsillectomy). Nearly 20-30\% of patients experience the side-effects like velopharyngeal insufficiency (up to one-third of patients), dry throat and swallowing difficulty ${ }^{85}$.

2. Genioglossus advancement with hyoid myotomy (GAHM):The GAHM involves the repositioning of genioglossus anteriorly through an inferior mandibular osteotomy (genioglossus advancement). This maneuver places the pharyngeal muscles and the base of the tongue on tension and expands the airway. The hyoid is suspended to the superior edge of the larynx and fixed in this position, adding to the effect of genioglossus advancement ${ }^{77}$.

3. Maxillomandibular advancement (MMA):It is obtained by osteotomy of the maxilla and mandibular. The advancement of the skeleton structures passively induces an anterior displacement of the soft palate and the tongue with a simultaneous widening of the pharyngeal space ${ }^{86}$. This procedure represents the most effective treatment after tracheotomy and has reported a mean reduction of $87 \%$ in $\mathrm{AHI}$. MMA is an invasive treatment presenting an aesthetic sequelae and complications. Therefore, this approach is reserved for selected patients when other modalities fail, as in patients with craniofacial abnormalities ${ }^{87}$.

4. Tracheostomy: This procedure relieves upper airway obstruction and its physiological consequences, thus representing the definitive treatment (virtually $100 \%$ effective) for $\mathrm{OSA}^{88}$. It is reserved for patients who do not respond to conservative treatment, in case of life-threatening arrhythmias or severe disability. It is a disfiguring procedure that decreases the patient's quality of life (QOL) with numerous adverse effects, such as, granuloma formation, speech difficulty, and stoma and airway infection ${ }^{8}$. 
5. Transoral robotic surgery: It was first introduced in March 2008 by Vicini and coworkers for the treatment of tongue base hypertrophy in $\mathrm{OSA}^{89}$. It is an effective treatment option for isolated retro lingual obstruction ${ }^{90}$. A study by Vicini et al. revised the 10-month polysomnography of 20 patients out of overall series of 44 operated cases. It was reported that a significant decrease of AHI occurs with success rate of $70 \%{ }^{91}$.

6. Hypoglossal nerve stimulation device: The electrical stimulation of the genioglossus muscle, the largest upper airway dilator muscle, causes tongue protrusion and stiffening of the anterior pharyngeal wall ${ }^{92}$. The first successful use of hypoglossal nerve stimulation to activate the genioglossus muscle was done by Schwartz and coworkers in 2001. A reduction in the severity of OSA in a small cohort of patients was reported ${ }^{93}$. The STAR trial is the largest ongoing clinical trial to assess sleep apnoea outcomes from hypoglossal nerve stimulation. The study outcomes have shown that improvements observed at one-year were sustained at the three-year follow-up mark. These include 78\% reduction in $\mathrm{AHI}$ events, $80 \%$ reduction in oxygen desaturation events, high adherence to therapy and improvements in quality of life $\mathrm{l}^{94}$.

The other procedures including distraction osteogenesis, rapid maxillary expansion, and laser midline glossectomy, lingual plasty, nasal surgery (septoplasty, turbinectomy, and polypectomy) may be useful as adjuncts to above mentioned measures.

\section{Conclusion}

Various mechanisms have been proposed for the development of hypertension in patients with OSA. The mostly agreed upon mechanisms include sympathetic activation, inflammation, activation of RAAS, oxidative stress and endothelial dysfunction. OSA acts as an essential cause of secondary hypertension. There is a growing body of literature which suggests that treatment of OSA in hypertensive patients lowers BP and improves the overall quality of life. However, more studies in different populations are required to demonstrate the effect of OSA treatment on cardiovascular and cerebrovascular health of a patient. In suspected cases of OSA a screening test should be undertaken followed by treatment of implicit OSA. Also, all cases of resistant hypertension should be screened for OSA and antihypertensive treatment should be combined with the treatment of OSA, wherever plausible. Thus, the issues of cardiovascular morbidity and mortality associated with OSA and hypertension can be addressed.

\section{Conflict Of Interest Statement}

The authors declare that there are no conflicts of interest regarding the publication of this paper.

\section{References}

1. Mills KT, Bundy JD, Kelly TN, et al. Global Disparities of Hypertension Prevalence and Control: A Systematic Analysis of Population-Based Studies From 90 Countries. Circulation. 2016 Aug 9; 134(6): 441-50.

2. World Health Organisation (WHO). Hypertension. [Online] 2018 [cited 2018 Jan 15]. Available from: URL:http://www.who.int/topics/ hypertension/en/

3. Anchala R, Kannuri NK, Pant $\mathrm{H}$, et al. Hypertension in India: a systemic review and meta-analysis of prevalence, awareness and control of hypertension. J Hypertens. 2014 Jan 22; 32(6): 1170-7.

4. Lim SS, Vos T, Flaxman AD, et al. A comparative risk assessment of burden of disease and injury attributable to 67 risk factors and risk factor clusters in 21 regions, 1990-2010: a systematic analysis for the Global Burden of Disease Study 2010. Lancet. 2012 Dec 15; 380(9859): 2224-60.

5. National Center for Health Statistics. Health, United States, 2016: With Chartbook on Long-term Trends in Health. Cent Dis Control 2017 May;314-7.

6. Whelton PK, Carey RM, AronowWS, et al. ACC/AHA/AAPA/ABC/ ACPM/AGS/APhA/ASH/ASPC/NMA/PCNA guideline for the prevention, detection, evaluation, and management of high blood pressure in adults. J Am Coll Cardiol. 2017 Nov; S0735-1097(17): 41519-1.

7. SpicuzzaL, Caruso D, Di Maria G. Obstructive sleep apnoea syndrome and its management. Ther Adv Chronic Dis. 2015; 6(5): 273-85.

8. Epstein LJ, Kristo D, Strollo PJ Jr, et al. Clinical guideline for the evaluation, management and long-term care of obstructive sleep apnea in adults. J Clin Sleep Med. 2009 Jun 15; 5(3): 263-76.

9. Young T, Peppard PE, Gottlieb DJ. Epidemiology of obstructive sleep apnea: A population health perspective. Am J Respir Crit Care Med. 2002 May 1; 165(9): 1217-39.

10. WoodsCE, Usher K, Maguire GP. Obstructive sleep apnoea in adult indigenous populations in high-income countries: an integrative review. Sleep Breath. 2015 Mar; 19(1): 45-53.

11. Park JG, Ramar K, Olson EJ. Updates on definition, consequences, and management of obstructive sleep apnea. Mayo Clin Proc. 2011 Jun; 86(6): 549-55.

12. Eastwood PR, Malhotra A, Palmer LJ, et al. Obstructive Sleep Apnoea: From pathogenesis to treatment: Current controversies and future directions. Respirology. 2010 May; 15(4): 587-95.

13. American Sleep Association. Sleep And Sleep Disorder Statistics. [Online]. 2018 [cited 2018 Feb 8];[1 screen]. Available from: URL:https://www.sleepassociation.org/sleep/sleep-statistics/

14. HeinzerR, Vat S, Marques-Vidal P, et al. Prevalence of sleep-disordered breathing in the general population: the HypnoLaus study. Lancet Respir Med. 2015 Apr; 3(4): 310-8.

15. Young T, Finn L, Peppard PE, et al. Sleep disordered breathing and mortality: eighteen-year follow-up of the Wisconsin sleep cohort. Sleep. 2008 Aug; 31(8): 1071-8.

16. Nieto FJ, Young TB, Lind BK, et al. Association of sleep-disordered breathing, sleep apnea, and hypertension in a large community-based study. Sleep Heart Health Study. JAMA. 2000 Apr 12; 283(14): 182936.

17. Marin J, Agusti A, Villar I, et al.Association between treated and untreated obstructive sleep apnea and risk of hypertension. JAMA 2012 May 23; 307(2): 2169-76.

18. HardingSM. Resistant hypertension and untreated severe sleep apnea: Slowly gaining insight.JClin Sleep Med. 2014 Aug 15; 10(8): 845-6.

19. Ahmad M, Makati D, Akbar S. Review of and Updates on Hypertension 
in Obstructive Sleep Apnea. Int J Hypertens. 2017 Sep 24; Article ID 1848375.

20. Grote L, Hedner J, Peter JH. Mean blood pressure, pulse pressure and grade of hypertension in untreated hypertensive patients with sleeprelated breathing disorder. JHypertens. 2001 Apr; 19(4): 683-90.

21. Peppard PE, Young T, Palta $M$, et al. Prospective study of the association between sleep disordered breathing and hypertension. N Eng J Med. 2000 May 11; 342(19): 1378-84.

22. Moroz VM, Shandra OA, Vastyanov RS, et al. Omelchenko OD editors Physiology. 2nd ed. Philadelphia: Wolters Kluwer Health/Lippincott Williams \& Wilkins; 2016

23. Trinder J, Kleiman J, Carrington $M$, et al.Autonomic activity during human sleep as a function of time and sleep stage. J Sleep Res. 2001 Dec; 10(4): 253-64.

24. Somers VK, Dyken ME, Mark AL, et al. Sympatheticnerve activity during sleep in normal subjects. N Engl J Med. 1993 Feb 4; 328(5): 303-7.

25. Mancia G. Autonomic modulation of the cardiovascular system during sleep. N Engl J Med. 1993 Feb 4; 328(5): 347-49

26. Mancia G, Fagard R, Narkiewicz K, et al. 2013 ESH/ESC guidelines for the management of arterial hypertension: The Task Force for the management of arterial hypertension of the European Society of Hypertension ( ESH ) and of the European Society of Cardiology (ESC). Eur Heart J. 2013 Jul 21; 34(28): 2159-219.

27. Endeshaw YW, White WB, Kutner M, et al. Sleep-Disordered Breathing and 24-Hour Blood Pressure Pattern Among Older Adults. J Gerontol A Biol Sci Med Sci. 2009 Feb; 64A(2): 280-5.

28. Waeber B, Mourad JJ, O’Brien E. Nighttime blood pressure: a target for therapy. Curr Hypertens Rep. 2010 Dec; 12(6): 474-9.

29. Boggia J, Li Y, Thijs L, et al.Prognostic accuracy of day versus night ambulatory blood pressure: a cohort study. Lancet. 2007 Oct 6 ; 370(9594): 1219-29.

30. Loredo JS, Nelesen R, Ancoli-Israel S, et al. Sleep quality and blood pressure dipping in normal subjects. Sleep. 2004 Sep 15; 27(6): 1097103.

31. Ancoli-Israel S, Stepnowsky C, Dimsdale J, et al. The effect of race and sleep-disordered breathing on nocturnal BP 'dipping': analysis in an older population.Chest. 2002 Oct; 122(4): 148-55.

32. Ohkubo T, Hozawa A, Nagai K, et al.Prediction of stroke by ambulatory blood pressure monitoring versus screening blood pressure measurements in a general population: the Ohasama study. J Hypertens. 2000 Jul; 18(7): 847-54.

33. Hansen TW, Li Y, Boggia J, et al. Predictive role of the nighttime blood pressure. Hypertension. 2011 Jan; 57(1): 3-10.

34. Henskens LH, Kroon AA, van Oostenbrugge RJ, et al.Associations of ambulatory blood pressure levels with white matter hyperintensity volumes in hypertensive patients. J Hypertens. 2009 Jul; 27 (7): 144652

35. Bisogni V, Pengo MF, Maiolino G, et al. The sympathetic nervous system and catecholamines metabolism in obstructive sleep apnoea. J Thorac Dis. 2016 Feb; 8(2): 243-54.

36. Parati G, Lombardi C, Hedner I, et al.Position paper on the management of patients with obstructive sleep apnea and hypertension: Joint recommendations by the European Society of Hypertension, by the European Respiratory Society and by the members of European COST (COoperation in Scientific and Technological Research) ACTION B26 on obstructive sleep apnea.J Hypertens. 2012 Apr; 30(4): 633-46.

37. Freet CS, Stoner JF, Tang X. Basic and Clinical Baroreflex and chemoreflex controls of sympathetic activity following intermittent hypoxia. Auton Neurosci. 2013 Mar; 174(1-2): 8-14.
38. Bradley TD, Floras JS. Obstructive sleep apnoea and its cardiovascular consequences. Lancet. 2009 Jan 3; 373(9657): 82-93.

39. Kario K. Obstructive sleep apnea syndrome and hypertension: mechanism of the linkage and 24-h blood pressure control. Hypertens Res. 2009Jul; 32(7): 537-41.

40. Brooks D, Horner RL, Kozar LF, et al. Obstructive sleep-apnea as a cause of systemic hypertension - evidence from a canine model. J Clin Invest. 1997 Jan 1; 99(1): 106-9.

41. Tamisier R, Pépin JL, Rémy J, et al. 14 nights of intermittent hypoxia elevate daytime blood pressure and sympathetic activity in healthy humans. Eur Respir J. 2011 Jan; 37(1): 119-28.

42. Unnikrishnan D, Jun J, Polotsky V. Inflammation in Sleep Apnea: An Update. Rev Endocr Metab Disord. 2015 Mar; 16(1): 25-34.

43. Sung KC, Suh JY, Kim BS, et al. High sensitivity C-reactive protein as an independent risk factor for essential hypertension. Am J Hypertens. 2003 Jun; 16(6): 429-33.

44. Ryan S, Taylor CT, McNicholas WT. Predictors of elevated nuclear factor-kappaB-dependent genes in obstructive sleep apnea syndrome. Am J Respir Crit Care Med. 2006 Oct 1; 174(7): 824-30.

45. Ciccone MM, Scicchitano P, Zito A, et al.Correlation between inflammatory markers of atherosclerosis and carotid intima-media thickness in Obstructive Sleep Apnea. Molecules. 2014 Jan 29; 19(2): 1651-62.

46. Totoson P,Fhayli W, Faury G, et al.Atorvastatin protects against deleterious cardiovascular consequences induced by chronic intermittent hypoxia.Exp Biol Med. 2013 Feb; 238(2): 223-32.

47. Moon JY. Recent update of renin-angiotensin-aldosterone system in the pathogenesis of hypertension. Electrolyte Blood Press. 2013 Dec; 11(2): 41-5.

48. Shimosawa T. Salt, the renin-angiotensin-aldosterone system and resistant hypertension. Hypertens Res. 2013 Aug; 36(8): 657-60.

49. Di Murro A, Petramala L, Cotesta D, et al. Renin-angiotensinaldosterone system in patients with sleep apnoea: prevalence of primary aldosteronism. JRenin-Angiotensin-Aldosterone Syst. 2010 Sep; 11(3): 165-72.

50. Foster GE, Hanly PJ, Ahmed SB, et al. Intermittent hypoxia increases arterial blood pressure in humans through a Renin-Angiotensin system-dependent mechanism. Hypertension. 2010 Sep; 56(3): 36977.

51. Jin ZN, Wei YX. Meta-analysis of effects of obstructive sleep apnea on the renin-angiotensin-aldosterone system. J Geriatr Cardiol 2016 May;13(4):333-43.52. Lavie, L. Oxidative stress in obstructive sleep apnea and intermittent hypoxia - Revisited - The bad ugly and good: Implications to the heart and brain. Sleep Med Rev. 2014; 20: 27-45.

52. Lavie L. Oxidative stress in obstructive sleep apnea and intermittent hypoxia - Revisited - The bad ugly and good: Implications to the heart and brain. Sleep Med Rev. 2015 Apr; 20: 27-45.

53. Eisele HJ, Markart P, Schulz R. Obstructive Sleep Apnea, Oxidative Stress, and Cardiovascular Disease: Evidence from Human Studies, Oxid Med Cell Longev. 2015; 2015: 608438

54. Pilkauskaite G, Miliauskas S, Sakalauskas R. Reactive Oxygen Species Production in Peripheral Blood Neutrophils of Obstructive Sleep Apnea Patients. Sci. World J. 2013 May 12; 2013: 421763.

55. Fedeli S, Negro V, Supino MC, et al. Evaluation of 8-isoprostane as a biomarker of oxidative stress in children with obstructive sleep apnea syndrome. Eur Respir J. 2012; 40 (suppl 56): 1073.

56. Carpagnano GE, Kharitonov SA, Resta 0, et al. 8-Isoprostane, a marker of oxidative stress, is increased in exhaled breath condensate of patients with obstructive sleep apnea after night and is reduced by 
continuous positive airway pressure therapy. Chest. 2003 Oct; 124(4): 1386-92.

57. Katz SL. Obstructive Sleep Apnea, Obesity, and Endothelial Dysfunction in Children. Am J Respir Crit Care Med. 2016 Nov 1; 194(9): 1046-7.

58. Hirata Y, Nagata D, Suzuki E, et al. Diagnosis and treatment of endothelial dysfunction in cardiovascular disease. Int Hear J. 2010 Jan; 51(1): 1-6.

59. Atkeson A, Yeh SY, Malhotra A, et al. Endothelial Function in Obstructive Sleep Apnea. Prog Cardiovasc Dis. 2009 Mar/Apr; 51(5): 351-62.

60. KneplerJrJL, Taher LN, Gupta MP, etal. Peroxynitrite causes endothelial cell monolayer barrier dysfunction. Am J Physiol. 2001 Sep; 281(3): C1064-75.

61. Patt BT, Jarjoura D, Haddad DN, et al.Endothelial Dysfunction in the Microcirculation of Patients with Obstructive Sleep Apnea. Am J Respir Crit Care Med. 2010 Dec 15; 182(12): 1540-5.

62. Jafari B, Mohsenin V. Endothelial dysfunction and hypertension in obstructive sleep apnea-Is it due to intermittent hypoxia?J Cardiovasc Dis Res. 2013 Jun; 4(2): 87-91.

63. Wolk R, Shamsuzzaman ASM, Somers VK. Obesity, Sleep Apnea, and Hypertension. Hypertension. 2003 Dec 11; 42(6): 1067-74.

64. Lavie P, Herer P, Hoffstein V. Obstructive sleep apnoea syndrome as a risk factor for hypertension: population study. BMJ. 2000 Feb 19; 320(7233): 479-82.

65. Jhamb M, Unruh M. Bidirectional relationship of hypertension with obstructive sleep apnea. Curr Opin Pulm Med. 2014 Nov; 20(6): 55864.

66. Muxfeldt ES, Margallo VS, Guimarães GM, et al. Prevalence and Associated Factors of Obstructive Sleep Apnea in Patients with Resistant Hypertension. Am J Hypertens. 2014 Aug; 27(8): 1069-78.

67. Pedrosa RP, Drager LF, Gonzaga CC, et al.Obstructive sleep apnea: the most common secondary cause of hypertension associated with resistant hypertension. Hypertension. 2011 Nov; 58(5): 811-7.

68. Demede M, Pandey A, Zizi F, et al.Resistant Hypertension and Obstructive Sleep Apnea in the Primary-Care Setting. Int J Hypertens. 2011; 2011: 340929.

69. Malhotra A, Huang Y, Fogel R, et al. Aging influences on pharyngeal anatomy and physiology: the predisposition to pharyngeal collapse. Am J Med. 2006 Jan; 119(1): 72e9-72.14.

70. Chang ET, Wang HM. Gender differences in obstructive sleep apnea syndrome. Eur Respir J. 2015; 46(supll 59): PA2363.

71. Armstrong C. Joint National Committee. Practice Guidelines JNC 8 Guidelines for the Management of Hypertension. Am Fam Physician. 2014 Oct 1; 90(7): 503-4.

72. Bratton DJ, Gaisl T, Wons AM, et al. CPAP vs mandibular advancement devices and blood pressure in patients with obstructive sleep apnea a systematic review and meta-analysis. JAMA. 2015; 314(21): 2280-93.

73. Scanlan MF, Roebuck T, Little PJ, et al. Effect of moderate alcohol upon obstructive sleep apnoea.Eur Respir J. 2000 Nov; 16(6): 909-13.

74. Köseoglu HI, Köktürk O, Ciftçi TU, et al. The Importance of Sleep Position in Obstructive Sleep Apnea Syndrome. Türk Toraks Derg. 2014; 15: 23-6.

75. Joosten SA, Hamilton GS, Naughton MT. Impact of Weight Loss Management in OSA. Chest. 2017 Jul; 152(1): 194-203.

76. Kapur VK, Auckley DH, Chowdhuri S, et al. Clinical Practice Guideline for Diagnostic Testing for Adult Obstructive Sleep Apnea: An American Academy of Sleep Medicine Clinical Practice Guideline. J Clin Sleep Med. 2017 Mar 15; 13(3): 479-504.
77. Downey R. Obstructive Sleep Apnea Treatment \& Management. [Online]. 2018 Jan 10 [cited 2018 Feb 17];[9 screens]. Available from: URL:https://emedicine.medscape.com/article/295807-treatment

78. Weinberger S, Cockrill B, Mandel J. Principles of Pulmonary Medicine. Principles of Pulmonary Medicine. 2008. https://doi.org/10.1016/ B978-1-4160-5034-6.X5001-5

79. Gupta MA, Simpson FC, Lyons DC. The effect of treating obstructive sleep apnea with positive airway pressure on depression and other subjective symptoms: A systematic review and meta-analysis. Sleep Med Rev. 2016 Aug; 28: 55-68.

80. Johnson KG, Johnson DC. Treatment of sleep-disordered breathing with positive airway pressure devices: technology update. Med Devices (Auckl). 2015 Oct 23; 8: 425-37.

81. Mansukhani MP, Kolla BP, Olson EJ, et al. Bilevel positive airway pressure for obstructive sleep apnea. Expert Rev Med Devices. 2014 May; 11(3): 283-94.

82. Sutherland K, Vanderveken OM, Tsuda H, et al. Oral Appliance Treatment for Obstructive Sleep Apnea: An Update. J Clin Sleep Med. 2014 Feb 15; 10(2): 215-27.

83. Ferguson KA, Cartwright R. Oral appliances for snoring and obstructive sleep apnea: a review. Sleep. 2006 Feb; 29(2): 244-62.

84. HoltyJ, Guilleminault C. Surgical options for the treatment of obstructive sleep apnea. Med Clin North Am. 2010 May; 94(3): 479-51.

85. Verse T, Hörmann K. The Surgical Treatment of Sleep-Related Upper Airway Obstruction. Dtsch Arztebl Int. 2011 Apr; 108(13): 216-21.

86. Prinsell JR. Maxillomandibular advancement surgery for obstructive sleep apnea syndrome. J Am Dent Assoc. 2002 Nov; 133(11): 1489-97.

87. Randerath WJ, Verbraecken J, Andreas S, et al. Non-CPAP therapies in obstructive sleep apnoea. Eur Respir J. 2011 May; 37(5): 1000-28.

88. Papadakis MA, McPhee SJ, editors. Current Medical Diagnosis \& Treatment. $5^{\text {th }}$ ed. New York: McGraw Hill Education; 2018.

89. Vicini C, Dallan I, Canzi P, et al. Transoral robotic tongue base resection in obstructive sleep apnoea-hypopnoea syndrome: A preliminary report. ORL J Otorhinolaryngol Relat Spec. 2010; 72(1): 22-7.

90. Meccariello G, Cammaroto G, Montevecchi F, et al. Transoral robotic surgery for the management of obstructive sleep apnea: a systematic review and meta-analysis. Eur ArchOtorhinolaryngol. 2017 Feb; 274(2): 647-53.

91. Vicini C, Dallan I, Canzi P, et al. Transoral robotic surgery of the tongue base in obstructive sleep Apnea-Hypopnea syndrome: anatomic considerations and clinical experience. Head Neck. 2012 Jan; 34(1): 15-22.

92. Eastwood PR, Barnes M, Walsh JH, et al. Treating obstructive sleep apnea with hypoglossal nerve stimulation.Sleep. 2011 Jul; 34(11): 1479-86.

93. Schwartz AR, Bennett ML, Smith PL, et al.Therapeutic electrical stimulation of the hypoglossal nerve in obstructive sleep apnea. Arch Otolaryngol Head Neck Surg. 2011 Oct; 127: 1216-23.

94. Woodson BT, Soose RJ, Gillespie MB, et al. Three-Year Outcomes of Cranial Nerve Stimulation for Obstructive Sleep Apnea: The STAR Trial. Otolaryngol Head Neck Surg. 2016 Jan; 154(1): 181-8.

95. Mubarik A, Burney W, Khan SA, et al. Prevalence of Comorbididites in Obstructive Sleep Apnea Population Waiting for Bariatric Surgery. J Gen Emerg Med. 2017 Sep 4; 2(6): 32.

96. Wali SO, Abalkhail B, Krayem A. Prevalence and risk factors of obstructive sleep apnea syndrome in a Saudi Arabian population. Ann Thorac Med. 2017 Apr 4; 12(2): 88-94.

97. Arnardottir ES, Bjornsdottir E, Olafsdottir KA, et al. Obstructive sleep apnoea in the general population: highly prevalent but minimal symptoms. Sleep. 2016 Jan; 47(1): 194-202. 
98. Shirani G, Morovati SP,ShamshiriAR, et al. Prevalence of Cardiovascular Disorders in Iranian Patients Suffering from Obstructive Sleep Apnea. J. Dent (Tehran). 2016; 13(3): 151-56.

99. Min HJ, Kim CH, Cho YJ, et al. Clinical Features of Obstructive Sleep Apnea That Determine Its High Prevalence in Resistant Hypertension. Yonsei Med J. 2015 Sep 1; 56(5): 1258-65.
100. Tkacova R, McNicholas WT, Javorsky M, et al.Nocturnal intermittent hypoxia predicts prevalent hypertension in the European Sleep Apnoea Database cohort study.Eur Respir J. 2014 Oct; 44(4): 931-41.

101. Gonçalves SC, Martinez D, Gus M, et al.Obstructive Sleep Apnea and Resistant Hypertension: A Case-Control Study. Chest. 2007 Dec; 132(6): 1858-62. 